\title{
Um estudo sobre a resolução de problemas com alunos surdos
}

\author{
A study on solving mathematical problems with deaf students
}

\author{
Aline Batista de Oliveira Martins \\ Rede Estadual de Educação do Paraná \\ aline_b.o.m@hotmail.com \\ ORCID:0000-0002-9578-7613
}

\author{
Andresa Maria Justulin \\ Universidade Tecnológica Federal do Paraná - UTFPR \\ Campus Cornélio Procópio \\ ajustulin@utfpr.edu.br \\ ORCID: 0000-0003-4107-8464
}

Resumo. Este trabalho analisou que elementos se revelam durante a resolução de problemas em formato vídeo gravado para Libras e em Língua Portuguesa escrita por alunos surdos. O caminho escolhido para o desenvolvimento deste trabalho tem caráter qualitativo e exploratório com estudo de caso, que permitiu investigar as contribuições possibilitadas pelo uso da Língua Brasileira de Sinais na Resolução de Problemas e compreender as principais dificuldades de alunos surdos em atividades de Resolução de Problemas sem o uso da Libras. A coleta de dados ocorreu por meio de entrevista semiestruturada com 3 (três) alunos, do $9^{\circ}$ ano, de uma escola que atende exclusivamente surdos da região norte do Paraná e também por meio da aplicação de uma prova com problemas matemáticos para os mesmos participantes. A última se deu em duas fases: na primeira, o aluno recebeu a prova em Língua Portuguesa e, na segunda, em Libras, cujo o objetivo foi descobrir as contribuições da Língua Brasileira de Sinais na interpretação de problemas matemáticos por alunos surdos. Os resultados apresentados indicaram que é irrelevante o problema ser proposto em Língua Portuguesa ou em Libras, pois os participantes apresentaram dificuldades na interpretação matemática do problema, bem como no conteúdo matemático relacionado. Portanto, mostrou-se necessário um ensino de Matemática adequado aos surdos e com abordagens metodológicas diferenciadas e próprias a esse público.

Palavras-chave. Resolução de problemas. Libras. Interpretação de problemas. Educação Matemática inclusiva. 


\begin{abstract}
This work analyzed which elements are revealed during the resolution of problems in recorded video format to Pounds and Portuguese written by deaf students. The path chosen for the development of this work has a qualitative and exploratory character with a case study which allowed to investigate the contributions made possible by the use of the Brazilian Sign Language in Problem Solving and to understand the main difficulties of deaf students in problem solving activities without the use of Libras. Data were collected through a semi structured interview with 3 (three) deaf students, from the 9th year from a school that caters exclusively to the deaf from the northern region of Paraná; And also, through the application of a test with mathematical problems for the 3 (three) deaf students, in two phases: in the first, the student will receive the test in Portuguese Language and, in the second, in Libras, whose objective was to discover the contributions of the Brazilian Sign Language in the interpretation of mathematical problems by deaf students. The results presented indicate it is irrelevant whether the problem is proposed in Portuguese or in Libras, since the participants presented difficulties in the mathematical interpretation of the problem, as well as in the related mathematical content. Therefore, it is necessary a mathematics teaching appropriate to deaf and whose differentiated teaching methodology and specific to this public.
\end{abstract}

Keywords. Problem solving. Libras. Interpretation of problems. Inclusive Mathematics Education.

Mathematics Subject Classification (MSC): primary 97D99.

\title{
1 Introdução
}

$\mathrm{Na}$ contemporaneidade, tem-se que a língua é parte integrante do desenvolvimento do ser humano, pois através dela ocorre a comunicação, a organização do pensamento e a socialização entre pessoas. No entanto, as pessoas surdas, historicamente, encontraram resistência de grande parte da sociedade à adoção de uma língua materna como a Língua Brasileira de Sinais (Libras).

A Libras, reconhecida pela Lei Federal $n^{0}$ 10.436, de 24 de abril de 2002, é utilizada por surdos para a comunicação entre eles e entre surdos 1 e ouvintes. O uso dessa língua não é apenas uma medida paliativa para a comunicação desse grupo de pessoas, mas é uma língua natural como qualquer outra, contém os níveis linguísticos fonológicos, morfológicos, sintáticos e semânticos, com apenas uma diferença em razão de sua modalidade

\footnotetext{
${ }^{1}$ Neste texto, o enfoque será o aluno surdo que faz uso da Libras como Língua natural e não de pessoas com deficiência auditiva.
} 
visuogestual em relação à língua oral. Segundo Brasil (1998, p. 12) “o léxico pode ser definido a 'grosso modo' como o conjunto de palavras de uma língua. No caso da Libras, as palavras ou itens lexicais são os sinais".

No ensino de Matemática, que registra índices insatisfatórios de aprendizagem em uma grande parcela de alunos, as aulas expositivas parecem corroborar esse cenário. Por outro lado, a resolução de problemas, outro campo teórico deste trabalho, mostra-se fundamental para o desenvolvimento do aluno em Matemática, pois os problemas o colocam diante de questionamentos, que permitem um desenvolvimento próprio do pensamento. A ação em questão possibilita o exercício do raciocínio lógico e não apenas o uso padronizado de regras.

Tal lacuna metodológica para o ensino indica a necessidade de saber, no sentido de conhecer a maneira de apresentar um problema matemático aos alunos surdos, se em Libras ou em Língua Portuguesa, e como isso influenciaria no entendimento para a resolução do problema. Nessa direção, a pergunta geratriz desta pesquisa foi: "Que elementos revelam-se durante a resolução de problemas em formato vídeo gravado para Libras e em Língua Portuguesa escrita por alunos surdos?”.

\section{Referencial Teórico}

\subsection{A comunicação por meio da Língua Brasileira de Sinais}

A comunicação é um processo de interação entre dois ou mais sujeitos, na qual são compartilhadas mensagens, ideias, emoções e sentimentos que podem influenciar a vida dos outros ([1] , 2012). No entanto, a comunicação oral, muitas vezes, não ocorre de forma clara, pois existem pessoas que nascem surdas. Quando existe a falta da audição, isso afeta grandemente o desenvolvimento da fala que, no caso das pessoas ouvintes, é o meio de comunicação usado.

Primeiramente, existem muitas formas de perceber e compreender o que é necessário para o desenvolvimento da linguagem da criança surda. Segundo Moura [7] (2014), a primeira é a estimulação auditiva, que ocorre com o uso de aparelhos de amplificação sonora e de um trabalho que possibilite o desenvolvimento da linguagem oral; a segunda acontece pela exposição precoce à língua de sinais, sua língua nativa, introduzida por meio da escrita; e a terceira é o domínio da Libras por parte da criança surda e de sua mãe.

No entanto, Nogueira e Zanqueta [9] (2013) asseguram que diversos autores defendem que a criança surda deve ser exposta à língua de sinais precocemente para se constituir no mundo, pois a língua oral gera uma grande dificuldade quando a criança não consegue 
ouvir. Então, sem a fala oral, os surdos se comunicam por meio de sinais, numa linguagem própria. Moura (2014) explica a importância de a criança surda conhecer a Libras o mais cedo possível:

\footnotetext{
É muito importante que a Libras esteja presente em seu universo da mesma forma que a língua oral está no universo das crianças ouvintes para que ela possa ser adquirida de forma completa, para que a criança surda possa dominála e se constituir como ser da linguagem. [8]
}

Assim, se a criança surda possuir o domínio da Libras como sua primeira língua, terá base para aprender a segunda, que é a Língua Portuguesa. Muitas vezes, entretanto, é difícil essa aquisição precoce de Libras pelas crianças surdas, pelo fato de que, na maioria das vezes, são filhas de pais ouvintes, que não conhecem Libras.

\subsection{A aprendizagem matemática por alunos surdos}

O fato de a Matemática possuir uma linguagem própria, com sinais específicos na Libras, como logaritmos, matrizes e funções, mas com conceitos desconhecidos pelos alunos, dificulta sobremaneira seu ensino. Isso ocorre também porque a Libras ainda é uma língua em construção e a maioria dos interpretes de Língua de Sinais possuem um conhecimento matemático superficial, o que pode promover ao aluno surdo dúvidas e uma grande dificuldade de aprendizagem (BORGES; NOGUEIRA, [3] 2013).

Segundo Silva [12] (2005), a Matemática precisa ser ensinada de forma contextualizada, para favorecer a ligação entre o conhecimento obtido em sala de aula com a realidade do estudante. É preciso que os professores adaptem suas aulas conforme a realidade de seus alunos, sendo eles ouvintes, surdos, cegos, ou portadores de outras deficiências.

Segundo Borges e Nogueira ([3], 2013, p. 50), essa não é uma tarefa fácil para o professor de Matemática,

[...] pois ao trabalharem temas matemáticos com alunos também ouvintes, passam pela difícil tarefa de interpretar os entes matemáticos, transpondo a apresentação desses temas originária dos manuais didáticos - dotados de conceitos matemáticos de difícil compreensão - para uma linguagem mais acessível e mais bem compreendida pelos alunos. [3]

Dessa forma, observa-se a difícil tarefa que os professores de Matemática possuem. Porém, a verdadeira complexidade está no papel do intérprete de língua de sinais, pois ele faz uma "interpretação de uma interpretação" (BORGES; NOGUEIRA,[3], 2013, p. 50). Assim, da interpretação que o professor de Matemática apresenta, o intérprete faz outra interpretação (em Libras) do conteúdo matemático para melhor compreensão do aluno surdo. Sem contar que, com a rapidez das falas dos professores em sala de aula, a barreira 
da transliteração para Libras é ampliada. Sendo que, assim, o intérprete realiza omissões das falas, o que pode afetar a compreensão do aluno surdo e alterar o que realmente foi dito (BORGES; NOGUEIRA, [3],2013).

Ocorre também a questão de que tanto o intérprete quanto o aluno surdo possuem um conhecimento insuficiente da Libras em relação aos conteúdos matemáticos, pela questão de a Libras ser uma língua viva e dinâmica e não abordar todos os sinais necessários para os conteúdos matemáticos, o que requer a utilização, muitas vezes, de classificadores.

Outro desafio que alunos surdos podem enfrentar é a dificuldade da compreensão da Língua Portuguesa escrita nos enunciados dos problemas matemáticos. Segundo Borges e Nogueira (2013), é comum alunos surdos inclusos demonstrarem desinteresse nas atividades de leitura e interpretação de texto.

É preciso que os professores percebam que, se eles possuírem uma boa formação, que permita a utilização de atividades que abranjam os alunos surdos inclusos, certamente alcançarão os demais alunos também. De acordo com Borges e Nogueira (2013, p. 67):

[...] Não são somente os alunos surdos que podem apresentar problemas de aprendizagem quando não ocorre uma comunicação e linguagem adequadas, mas também qualquer aluno ouvinte, que comungue de uma língua comum com a professora. [3]

A escolha do problema e da abordagem parece facilitar a aprendizagem de alunos surdos. Na próxima seção, será investigada a resolução de problemas do ponto de vista da aprendizagem.

\subsection{A Resolução de Problemas}

As indicações apresentadas nesta seção referem-se ao uso da resolução de problemas no ensino de Matemática, de maneira geral. Segundo Lupinacci e Botin ([6],2004), "A Resolução de Problemas é um método eficaz para desenvolver o raciocínio e para motivar os alunos para o estudo da Matemática" (p. 01).

Por problema matemático, os Parâmetros Curriculares Nacionais ([4], 1998, p. 41), definem que:

\footnotetext{
Um problema matemático é uma situação que demanda a realização de uma sequência de ações ou operações para obter um resultado. Ou seja, a solução não está disponível de início, no entanto é possível construí-la. Em muitos casos, os problemas usualmente apresentados aos alunos não constituem verdadeiros problemas porque, via de regra, não existe um real desafio nem a necessidade de verificação para validar o processo de solução. [4]
}

Assim, os problemas são fundamentais na aprendizagem da Matemática, pois por meio deles, o aluno é colocado diante de questionamentos, que permitem um desenvol- 
vimento próprio do pensamento, possibilitando o exercício do raciocínio lógico e não apenas o uso padronizado de regras.

Corroborando esse entendimento, a Base Nacional Comum Curricular (BNCC), ([4], 2017, p. 264), destaca que:

\begin{abstract}
Os processos matemáticos de resolução de problemas, de investigação, de desenvolvimento de projetos e da modelagem podem ser citados como formas privilegiadas da atividade Matemática, motivo pelo qual são, ao mesmo tempo, objeto e estratégia para a aprendizagem ao longo de todo o Ensino Fundamental. Esses processos de aprendizagem são potencialmente ricos para o desenvolvimento de competências fundamentais para o letramento matemático (raciocínio, representação, comunicação e argumentação) e para o desenvolvimento do pensamento computacional. [5]
\end{abstract}

Polya ([10],2006) apresenta quatro etapas para a resolução de problemas, que ficaram conhecidas como "passos de Polya". Essas etapas deveriam ser percorridas por todas as pessoas que pretendem resolver um problema e obter êxito no processo: compreensão do problema; estabelecimento de um plano; execução do plano; e retrospecto - são realizadas pelo aluno, ou seja, elas refletem passos necessários para se resolver o problema. Abaixo, o detalhamento de cada etapa.

Na primeira etapa, a compreensão do problema, os alunos (ou resolvedores do problema) devem se questionar sobre: qual é a incógnita? Quais são os dados? Qual é a condição? Ou seja, eles terão que identificar os dados existentes no problema e perceber se a condição é (ou não) suficiente para se determinar a incógnita. Dessa forma, será possível eles pensarem uma estratégia para a resolução do problema.

$\mathrm{Na}$ segunda etapa, o estabelecimento de um plano, os alunos devem encontrar uma conexão entre os dados e a incógnita do problema. Nesse momento, eles podem pensar se já resolveram algum problema similar ou algum problema que empregasse o raciocínio para a resolução desse novo problema. Em caso positivo, ou seja, se eles lembrarem de um problema correlatado, então terão que se questionar se é possível a utilização da mesma estratégia ou do mesmo método. Assim, eles traçarão um plano para a resolução do problema em questão.

$\mathrm{Na}$ terceira etapa, a execução do plano, os alunos devem executar o plano, sempre questionando se cada passo dessa execução está correto.

$\mathrm{Na}$ quarta etapa, o retrospecto, os resolvedores devem examinar a solução obtida, ou seja, fazer a validação do resultado e do argumento. Nessa etapa, precisam se questionar se existe alguma alternativa diferente que possibilite chegar ao mesmo resultado ou se eles poderiam utilizar esse plano construído em algum outro problema.

Apesar de não ser foco deste estudo a análise do uso das etapas de Polya com alunos surdos, é necessário conhecê-las. Este trabalho tratará da primeira etapa, ou seja, do pro- 
cesso de interpretação do problema, que envolve a leitura do problema, a identificação da informação necessária e, no caso dos alunos surdos, também se relaciona com o domínio da Língua Portuguesa e de suas particularidades e da Libras e de suas características.

\section{Método, procedimentos e participantes da pesquisa}

A pergunta diretriz desta pesquisa é: "Que elementos revelam-se durante a resolução de problemas em formato vídeo gravado para Libras e em Língua Portuguesa escrita por alunos surdos?". A partir dela, foram definidos os seguintes objetivos: investigar as contribuições possibilitadas pelo uso da Língua Brasileira de Sinais na resolução de problemas e compreender as principais dificuldades de alunos surdos em atividades de resolução de problemas sem o uso da Língua Brasileira de Sinais.

Esta pesquisa, quanto aos seus objetivos, foi de natureza exploratória, e utilizou o estudo de caso como método de pesquisa. Segundo Bogdan e Biklen ([2],1994), a pesquisa qualitativa apresenta-se como uma tentativa para a compreensão mais detalhada dos significados e características situacionais. A pesquisa qualitativa é rica em dados descritivos obtidos no contato direto do pesquisador com o sujeito da pesquisa, com o ambiente e com as conversas, preocupando-se em retratar a perspectiva dos participantes. A abordagem qualitativa privilegia a compreensão dos comportamentos, dos valores, das crenças, das representações, das opiniões e das atitudes.

Nesse tipo de pesquisa, o pesquisador investiga o sujeito a fim de compreender aquilo que ele experimenta, ou como interpreta suas experiências, e o modo como compreende o ambiente em que convive. Por essa razão, a presente pesquisa, ao investigar como os alunos surdos "veem" e entendem a Matemática e identificar as contribuições possibilitadas pelo uso da Libras na interpretação de problemas matemáticos por alunos surdos, identifica-se como qualitativa.

Foram participantes da pesquisa três alunos do $9^{\circ}$ ano do Ensino Fundamental de uma escola especializada em atender alunos surdos da região norte do Paraná. A instituição e os responsáveis dos alunos concordaram com a participação e assinaram o termo de consentimento livre e esclarecido.

A coleta de dados desta pesquisa ocorreu por meio da aplicação de uma prova com problemas matemáticos e entrevista semiestruturada: A aplicação da prova ocorreu em duas fases: na primeira, o aluno recebeu a prova escrita na Língua Portuguesa; e na segunda, ele recebeu a mesma prova, em Libras, por meio de vídeo. Os problemas escolhidos para constituir a prova abordavam conteúdos anteriores ao ano em que os alunos estavam. A entrevista semiestruturada foi realizada em Libras, com ajuda de um interprete de Libras e por meio dela foi possível compreender: o grau de surdez de cada aluno; 
como foi a descoberta da Libras; se já estudaram em escolas inclusivas; as dificuldades encontradas na Matemática; e as dificuldades percebidas na prova em Língua Portuguesa e em Libras.

\section{Análise dos dados}

\subsection{A Entrevista e os participantes}

A surdez do Aluno 1 é congênita, ou seja, ele é surdo de nascença. Com dois anos, foi levado a um Instituto para surdos, onde conheceu e aprendeu a Libras, o que, segundo ele, foi mais fácil, pois existiu um "sentimento de correspondência" com a Libras, já que ele consegue conversar e se expressar através dela.

O Aluno 2 nasceu ouvinte, mas dois meses após seu nascimento, por motivo de uma doença, perdeu a audição. Dessa forma, foi levado ao Instituto para surdos para aprender Libras. Como ele não entende leitura labial, disse que "Libras é tudo para ele!" e se tornou sua forma de comunicação.

O Aluno 3 possui surdez congênita e, por essa razão, foi levado ao Instituto para surdos. Lá, ele teve contato e conhecimento sobre a Libras. Para ele, a Libras "é tudo", pois é o seu meio de comunicação.

\subsubsection{Resolução de problemas, a Língua Portuguesa e a Libras}

Quando interrogado sobre sua preferência entre Libras ou Língua Portuguesa, o Aluno 1 responde ter preferência pela Libras, mas, na prova, ele relata que sua dificuldade foi a Matemática. Para ele, não foi relevante a língua na qual a prova estava, ele não conseguiria resolver o problema de maneira nenhuma.

Já o Aluno 2, quando questionado sobre a preferência entre a prova em Libras ou em Língua Portuguesa, ele relata não ter preferência, sendo indiferente. O participante diz que: "Seria em português para que eu pudesse ler ou em Libras para que eu pudesse ver". Sobre a prova, ele disse não saber o que alguns problemas exigiam dele, ou seja, não soube como interpretar alguns problemas.

O Aluno 3 expressa sua preferência pela Libras, justificando ter dificuldade no significado de algumas palavras na Língua Portuguesa. Sobre a prova de Matemática, ele relatou não saber o que os problemas demandavam para a solução, mostrando também dificuldade na interpretação.

Por meio dos dados obtidos pela entrevista, foi possível perceber que a dificuldade dos alunos surdos na resolução da prova relaciona-se à interpretação dos problemas matemáticos e não à língua em que eles são apresentados, visto que compreenderam as palavras 
mas não o contexto matemático. Dessa forma, percebe-se que existe a falta de conhecimento matemático e de raciocínio lógico por parte desses alunos. Visando superar essas dificuldades é recomendado que seja utilizada, nas aulas de Matemática, a metodologia de resolução de problemas, que possibilita aos alunos a construção do raciocínio lógico e não apenas o uso padronizado de regras.

\subsection{Análise da Prova}

Os problemas serão discutidos em ordem sequencial. Primeiramente, será analisada sua resolução em Língua Portuguesa e, depois, em Libras.

\section{Quadro 1: Problema 1.}

Problema 1: Paulo pretende comprar um televisor novo. Sabe-se que seu salário é o dobro do salário de seu irmão Júlio, o qual ganha $\mathrm{R} \$ 1341,90$. No próximo sábado, ele irá comprar o televisor e pagar a conta de água, no valor de $\mathrm{R} \$ 43,54$. Após pagar à vista a televisão e a conta de água, Paulo calculou que lhe sobrarão exatamente R $\$ 1220,02$ de seu salário. Levando estes dados em consideração, qual será a despesa total de Paulo no sábado?

\section{O Aluno 1}

Na prova em Língua Portuguesa, o Aluno 1 não conseguiu interpretar o que o problema solicitava, conforme Figura 1. Ele não compreendeu que o salário de Paulo era o dobro de seu irmão, e o aluno apenas indicou o dado de que o salário seria de $\mathrm{R} \$ 1341,90$.

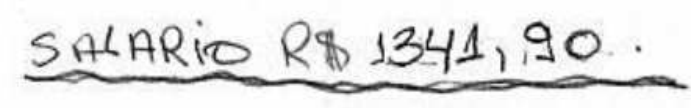

Figura 1: Resolução da Prova em Português pelo Aluno 1.

Fonte: Dados da pesquisa.

Na prova em Libras, o Aluno 1 apenas indicou o valor da água, o que mostra que ele não sabia o que fazer com os dados do problema, não sabendo interpretá-lo. Conforme figura 2 .

$$
\text { Julio áte Sálodo } 43,54]
$$

Figura 2: Resolução da Prova em Libras pelo Aluno 1.

Fonte: Dados da pesquisa. 
O Aluno 1 demonstrou não compreender o que estava sendo proposto no primeiro problema. Tanto na prova em Língua Portuguesa quanto em Libras, ele não conseguiu perceber alguma conexão entre os dados, e nem mesmo elaborar um plano para resolução desse problema. Assim, percebe-se a falta de conhecimento matemático para resolução do problema, ou seja, a dificuldade do Aluno 1 não está associada ao Português ou à Libras, mas sim à Matemática.

\section{O Aluno 2}

Na prova em Língua Portuguesa, o Aluno 2 não compreendeu que o salário de Paulo era o dobro do de seu irmão e, assim, ele descontou o valor da água do salário que ele acreditou ser o de Paulo, Figura 3. Porém, ele não percebeu que o problema já mostrava o valor restante do salário de Paulo após o gasto de sábado. Diante disso, ele encontrou outro valor restante e fez a subtração entre eles, que seria o valor da televisão, não sendo o que o problema pedia.

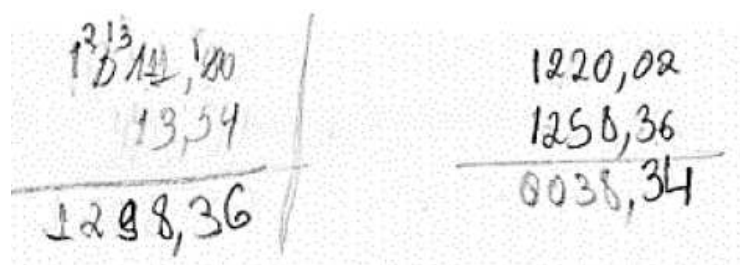

Figura 3: Resolução da Prova em Português pelo Aluno 2.

Fonte: Dados da pesquisa.

Na prova em Libras, como se pode notar na Figura 4, o Aluno 2 também não conseguiu compreender que o salário de Paulo era o dobro do de seu irmão e, ao invés disso, ele associou o salário de Paulo ao valor da sobra de sábado dado pelo problema. Ele fez a separação entre o salário de Paulo e de Júlio e descontou o valor da água do salário dos dois irmãos. Dessa forma, ele apresentou o restante do salário de cada um dos dois, após o pagamento da água e se esqueceu da compra da televisão.

O Aluno 2 apresentou ter compreendido o problema melhor na prova em Língua Portuguesa do que na em Libras. Na primeira prova, ele identificou os dados, planejou e executou um plano. Porém, na prova em Libras, ele se apresentou um pouco confuso sobre de qual salário deveria descobrir o gasto.

\section{O Aluno 3}

Na prova em Libras, o Aluno 3 apenas copiou dados do problema para não deixar a prova em branco, pois se encontrava indisposto para resolvê-la por problemas pessoais. Assim, 

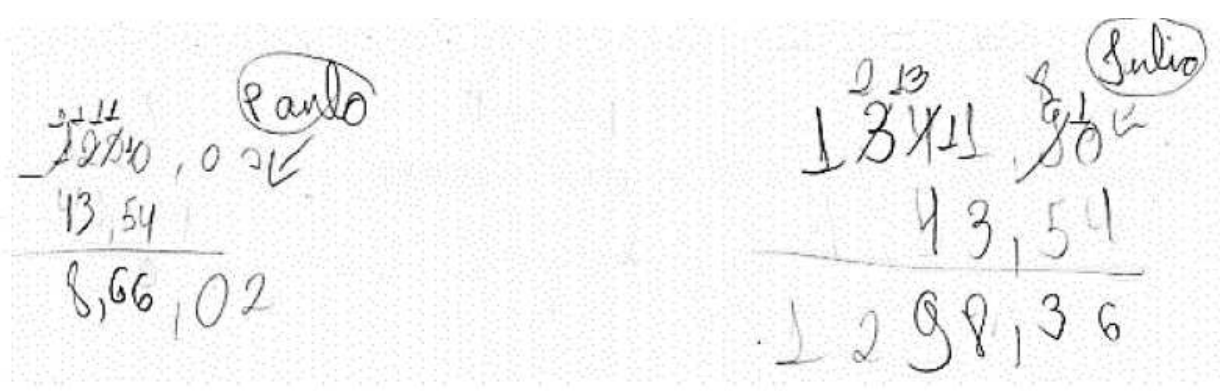

Figura 4: Resolução da Prova em Libras pelo Aluno 2.

Fonte: Dados da pesquisa.

a prova em Libras desse aluno não será analisada.

Na prova em Língua Portuguesa, esse aluno apresentou dificuldade na interpretação do problema e em operações matemáticas elementares. Na Figura 5, o registro mostra que ele não conseguiu compreender que o salário de Paulo era o dobro do de seu irmão, utilizando o salário de Júlio como sendo o de Paulo. Porém, ele conseguiu identificar alguns dados e esquematizou um plano. Nele, o participante descontou o valor da água do salário de Paulo e, logo após, subtraiu-o do valor de $\mathrm{R} \$ 1220,00$, que sobraria no sábado após os gastos. No entanto, através desse procedimento, ele obteria o valor da televisão e não o valor gasto por Paulo no sábado. O Aluno 3, assim como os demais, demonstrou dificuldade na interpretação do problema.

Além disso, também foi possível perceber que esse aluno resolveu a subtração de forma incorreta, pois não respeitou a ordem das unidades, colocando os valores em qualquer lugar. Também não respeitou as vírgulas, o que o levou ao erro. Dessa forma, percebe-se que o aluno também tem dificuldade na operação de subtração.

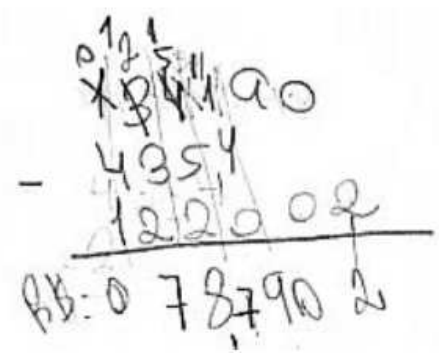

Figura 5: Resolução da Prova em Português pelo Aluno 3.

Fonte: Dados da pesquisa.

No problema 1, o Aluno 3 apresentou ter dificuldade tanto na interpretação do problema quanto na operação matemática necessária para resolver o problema. Dessa forma, percebe-se que a dificuldade do Aluno 3 não está associada à Língua Portuguesa ou à Libras, mas sim à Matemática. 
Quadro 2: Problema 2.

Problema 2: Um professor tem de ler 32 trabalhos de seus alunos. Nos primeiros 40 minutos, ele lê 5 . Admitindo-se que ele continue a ler no mesmo ritmo, quanto tempo levará para ler todos os trabalhos?

\section{O Aluno 1}

Na prova em Língua Portuguesa, esse aluno não conseguiu interpretar o problema, questionando se era 5 minutos por trabalho - Figura 6. Ele teve essa dificuldade na interpretação, o que o levou a não conseguir uma solução para o problema.

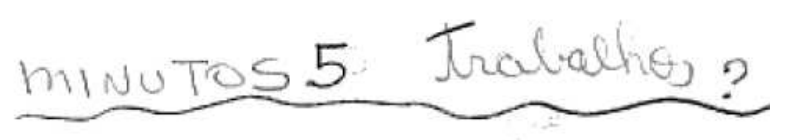

Figura 6: Resolução da Prova em Português pelo Aluno 1.

Fonte: Dados da pesquisa.

Já na prova em Libras, esse aluno também não compreendeu os dados do problema. Assim, supõe-se que ele apenas deduziu que o professor leria os 32 trabalhos em 5 minutos, conforme Figura 7.

\section{TRABALHO 32 frimsiros ate é 5 minitiss}

Figura 7: Resolução da Prova em Libras pelo Aluno 1.

Fonte: Dados da pesquisa.

No problema 2, o Aluno 1 não compreendeu o que estava sendo proposto na prova em Língua Portuguesa. Na prova em Libras, exibiu um possível tempo que o professor levaria para ler todos os trabalhos. Segundo ele, esse era o questionamento do problema. Mas nem mesmo na prova em Libras ele conseguiu perceber alguma conexão entre os dados ou elaborar um plano para solução desse problema.

Assim, percebe-se a falta do conhecimento matemático para a resolução do problema, ou seja, a dificuldade desse aluno não estava associada apenas à Língua Portuguesa, mas também à Matemática.

\section{O Aluno 2}

Na prova em Língua Portuguesa, conforme Figura 8, o aluno considerou que o professor levaria 5 minutos para ler os 32 trabalhos. 


\section{5 minutas}

Figura 8: Resolução da Prova em Português pelo Aluno 2.

Fonte: Dados da pesquisa.

Já na prova em Libras, conforme Figura 9, possivelmente o aluno raciocinou da seguinte maneira: Se o professor lê 5 trabalhos em 40 minutos, então ele levará talvez 1 hora para ler todos os trabalhos.

\section{TALvel por 1 heras}

Figura 9: Resolução da Prova em Libras pelo Aluno 2.

Fonte: Dados da pesquisa.

No problema 2, o Aluno 2 demonstrou um melhor entendimento na prova em Libras, pois ele compreendeu que o professor levaria mais tempo para ler todos os trabalhos. $\mathrm{Na}$ prova em Língua Portuguesa, existiu falta de raciocínio lógico ao afirmar que o professor levaria 5 minutos para ler os 32 trabalhos, ou seja, a estimativa do aluno não foi adequada. Já na prova em Libras, o aluno indicou que esse tempo seria maior, talvez de uma hora.

\section{O Aluno 3}

No segundo problema, conforme Figura 10, o aluno deduziu que o professor levaria 30 minutos para ler os 32 trabalhos. Assim, ele não utilizou os dados do enunciado para resolver o problema.

$$
\text { 30. muntos }
$$

Figura 10: Resolução da Prova em Português pelo Aluno 3.

Fonte: Dados da pesquisa.

No Problema 2, o Aluno 3 supôs que o professor levaria 30 minutos para ler os 32 trabalhos. Os dados do problema informam que o professor leva 40 minutos para ler apenas 5 trabalhos, ou seja, a estimativa desse aluno não foi razoável.

\subsection{Buscando elementos e relações}

$\mathrm{Na}$ Matemática, assim como os ouvintes, os surdos podem apresentar dificuldades na compreensão dos conceitos. As razões podem ser diversas como a abordagem realizada 
pelo professor ou mesmo a falta de materiais para auxiliá-lo no ensino de Matemática para alunos surdos.

$\mathrm{Na}$ tentativa de investigar as dificuldades que a Língua Portuguesa poderia provocar na aprendizagem matemática de alunos surdos, aplicou-se a mesma prova em Língua Portuguesa e em Libras. Na prova em Língua Portuguesa, os alunos surdos não conseguiram resolver os problemas, apresentando dificuldades na interpretação. Com a aplicação da prova em Libras, esperava-se que o contrário acontecesse, ou seja, que os surdos realizassem a prova com mais facilidade. No entanto, não houve diferença, pois nem mesmo na prova em Libras os alunos conseguiram interpretar ou resolver os problemas. Na entrevista, o Aluno 2 revelou preferir a prova em Língua Portuguesa, dizendo que o ideal seria nas duas línguas.

Por meio das análises realizadas sobre as resoluções dos alunos surdos nas provas aplicadas em Língua Portuguesa e em Libras, pode-se afirmar que a dificuldade dos alunos não está associada apenas à Língua Portuguesa. Dessa forma, somente a tradução não foi suficiente para que os alunos participantes resolvessem os problemas matemáticos. Eles não conseguiram utilizar o conteúdo matemático para a resolução de problemas e demonstraram dificuldades em conceitos e operações elementares da Matemática.

A relação entre a Língua Portuguesa e a Matemática mostrou-se frágil, pois os alunos surdos mostraram dificuldade na leitura e na compreensão dos problemas e, sem a compreensão, não há como resolvê-los. Além disso, essas duas disciplinas possuem uma linguagem própria, sendo preciso dominá-las para se comunicar e interagir por meio delas. No caso do surdo, é preciso o domínio da Língua Portuguesa para que ocorra o domínio da Matemática. O aluno necessita ter "a percepção da estrutura do contexto verbal do problema e a passagem desta para a linguagem matemática" ([8], 2007, p. 4).

Entre a Língua Portuguesa e a Libras existe uma relação de tradução, ou seja, a conversão de uma língua para outra, já que se trata de uma língua escrita. No caso dos participantes, alunos de uma escola para surdos, já havia o domínio da Libras, sendo considerados bilíngues. Entre a Libras e a Matemática notou-se a ausência de conceitos matemáticos. A abstração do conteúdo matemático pode dificultar a aprendizagem dessa disciplina pelos alunos surdos e, sem ela, não há base para se resolver um problema. Corroborando os estudos de Rocha ([11], 2015), em nada adiantará que o surdo faça uma prova em Libras se ele não tiver a possibilidade de aprender os conteúdos científicos que lhe são necessários para o enfrentamento da prova, pois, com ou sem Libras, ele precisará resolver os problemas propostos. 


\section{Considerações finais}

Dessa forma, a contribuição da Libras aos alunos surdos na resolução de problemas matemáticos ficou restrita a essa esfera, pois eles necessitam muito mais do que apenas uma tradução da Língua Portuguesa para a Libras. Eles carecem de um conhecimento matemático que os auxiliem a: identificar dados em um problema; planejar uma estratégia para solução; e executar essa estratégia e analisar se foi alcançado o resultado esperado do problema. E eles só obterão esse conhecimento quando forem frequentemente colocados diante de situações-problemas que os levem a estimular seu raciocínio lógico.

Muitas vezes, a tradução da Língua Portuguesa para a Libras pode ser prejudicial para os alunos surdos no momento de interpretar problemas, pois essa tradução pode confundilos, como ocorrido com o Aluno 2 na resolução da prova em Libras.

Desse modo, considera-se a necessidade de um ensino de Matemática que seja adequado a esse público e cuja metodologia de ensino apoie-se na visualização e na experimentação matemática.

Ao concluir esta pesquisa inicial, fica a sensação de desafio, de aventura-se em um campo que pode ser muito explorado. Os surdos merecem mais do que o nosso respeito, merecem ter as mesmas oportunidades para que possam, de fato, aprender e desfrutar da Matemática como construção humana.

\section{Referências}

[1] ALMEIDA, M. F. O. A importância da comunicação em LIBRAS na vida das pessoas surdas. In: Portal Educação. Disponível em: https:// www.portaleducacao.com.br/educacao/artigos/22074/aimportancia-da-comunicacao-em-Libras-na-vida-das $\backslash-$ pessoas-surdas. Acesso em 26 set. 2016.

[2] BOGDAN, R. C.; BIKLEN, S. K. Investigação qualitativa em educação: uma introdução à teoria e aos métodos. Portugal: Porto, 1994.

[3] BORGES, F. A; NOGUEIRA, C. M. I. Um panorama da inclusão de estudantes surdos nas aulas de matemática. In: NOGUEIRA, C. M. I. (ORG.). Surdez, Inclusão e Matemática. Curitiba: CRV, p. 43-70, 2013.

[4] BRASIL. Ministério da Educação. Secretaria de Educação Fundamental. Parâmetros Curriculares Nacionais: Matemática. ( $3^{\circ}$ e $4^{\circ}$ ciclos do ensino fundamental). Brasília: MEC, 1998. Disponível em http: / / cptstatic.s3.amazonaws. $\mathrm{com} / \mathrm{pdf} / \mathrm{cpt} / \mathrm{pcn} / \mathrm{volume-03-matematica.pdf.}$ 
[5] BRITO, L. F. A Língua Brasileira de Sinais. 1998, 64p. Disponível em: https://www.librasgerais.com.br/materiais-inclusivos/ downloads/gramatica-libras.pdf. Acesso em: 30 jan 2019.

[6] LUPINACCI, M. L. V. e BOTIN, M. L. M. Resolução de problemas no ensino de matemática. In: ANAIS DO VIII ENCONTRO NACIONAL DE EDUCAÇÂO MATEMÀTICA, Recife, 2004. p. 1-5. Disponível em: http: / / www . sbembrasil.org.br/files/viii/pdf/02/MC18361331034.pdf.

[7] MOURA, M. C. Surdez e linguagem. In: LACERDA, C. B. F; SANTOS, L. F. (ORG.). Tenho um aluno surdo, e agora? Introdução à LIBRAS e educação de surdos. São Carlos: EdUFSCar, p. 13-26, 2014.

[8] NETO, M. O. T. Os significados produzidos por estudantes durante a resolução de problemas em Matemática. Disponível em: http://www.sbem. com.br/files/ix_enem/Comunicacao_Cientifica/Trabalhos/ CC15493997215T.rtf. Acesso em: 29 mai 2018.

[9] NOGUEIRA, C. M. I; ZANQUETA, M. E. M. T. Surdez, Bilinguismo e o Ensino Tradicional da Matemática. In: NOGUEIRA, C. M. I (ORG.). Surdez, Inclusão e Matemática. Curitiba: CRV, p. 23-41, 2013.

[10] POLYA, G. A arte de resolver problemas. Tradução de Heitor Lisboa de Araújo. Rio de Janeiro: Editora Interciência, 2006.

[11] ROCHA, L. R. M. O que dizem surdos e gestores sobre vestibulares em Libras para ingresso em Universidades Federais. 2015. 127 f. Dissertação (Programa de Pós-Graduação em Educação Especial), Universidade Federal de São Carlos. São Carlos: UFSCar, 2015. p.125.

[12] SILVA, J. A. F. Refletindo sobre as dificuldades de aprendizagem na Matemática: algumas considerações. Dissertação (Trabalho de Conclusão de Curso) - Universidade Católica de Brasília, Brasília, 2005. 11p. Disponível em: https://www.ucb.br/sites/100/103/TCC/22005/ JoseAugustoFlorentinodaSilva.pdf.

Submetido em 23 jun. 2020

Aceito em 13 nov. 2020 